\title{
Characteristics of high carbon ash as a raw material for spontaneous combustion inhibitor and its field demonstration
}

Seok Un Park ( $\square$ seokun.park@kepco.co.kr)

Korea Electric Power Corporation Research Institute Jae Kwan Kim

Korea Electric Power Corporation Research Institute

Dong lk Shin

Korea Electric Power Corporation Research Institute

\section{Research}

Keywords: High carbon ash, spontaneous combustion, inhibitor, coal yard

Posted Date: April 28th, 2020

DOI: https://doi.org/10.21203/rs.3.rs-23927/v1

License: (c) (i) This work is licensed under a Creative Commons Attribution 4.0 International License.

Read Full License 


\title{
Characteristics of high carbon ash as a raw material for spontaneous combustion inhibitor and its field demonstration
}

\author{
Seok Un Park1, Jae Kwan Kimı, Dong Ik Shinı
}

${ }_{1}$ Korea Electric Power Corporation Research Institute, 105 Munji-ro, Yuseong-gu, Daejeon, 34056, Republic of

Korea

\begin{abstract}
In this study, we examined the physical chemistry, fuel characteristics and combustion reactivity of high carbon ash as a raw material for spontaneous combustion inhibitor in order to solve the problem of spontaneous combustion which has been often occurring in coal yard of coal-fired power plants in Korea. The high carbon ash has higher activation energy and lower frequency factor than bituminous coal, so combustion began at a relatively higher temperature than bituminous coal. In case of fly ash, the heat transfer characteristics were better than those of bottom ash and pond ash, and in case of coarse particles of fly ash, they were found to be highly applicable as a raw material for spontaneous combustion inhibitor due to their relatively high unburned carbon content. As a result of manufacturing spontaneous combustion inhibitors along with asphalt and PFAD (palm fatty acid distillate), the contact angle to water was more than $90^{\circ}$ regardless of the mixing ratio, showing hydrophobic surface characteristics, and it was found that the hardness and viscosity of spontaneous combustion inhibitors increased as the mixing ratio of high carbon ash increased. In addition, when spontaneous combustion inhibitors manufactured were applied to coal stockpiles in coal yard at coal-fired power plants, there was little change in the internal temperature of coal stockpiles and the highest value of instantaneous increasing rate per minute was found to be lowered from $1.60^{\circ} \mathrm{C} / \mathrm{min}$ to $0.061^{\circ} \mathrm{C} / \mathrm{min}$, indicating that spontaneous combustion inhibitors using high carbon coal ash had a great effect of preventing spontaneous combustion.
\end{abstract}

Key Words: High carbon ash; spontaneous combustion; inhibitor; coal yard

*Corresponding author 
Email: seokun.park@kepco.co.kr

Tel: +82-42-865-5664 Fax: +82-42-865-5669

\section{Introduction}

The most recent major issues of coal-fired power plants in Korea are the disposal of coal ash, which occurs after burning coal, and the spontaneous combustion of coal from coal yard. Coal ash generated from the five coal-fired power generation companies in Korea amounts to about 7.92 million tons (18), of which the high carbon ash amounts to about 1.87 million tons. High carbon ash refers to coal ash with an unburned carbon content of more than 5 percent of coal ash under the Korea Quality Standard (KS L 5405), and occurs when combustion is unstable or the combustion efficiency is reduced due to the increase or decrease in output of electric power generation caused by the entry of the system of renewable energy such as solar power and etc. In general, coal ash has many potential usability characteristics in various fields such as construction industry, soil improvement, ceramic, zeolite synthesis, catalyst and precious metal recovery (Yawen et al., 2019), and is mainly used as a cement concrete mix in Korea. However, the high carbon ash is not able to be recycled as a cement concrete mix because it does not meet the specifications of the class- 2 of coal ash and must be buried in the ash pond. Moreover, the generation of high carbon ash is on the rise due to the increase in the use of low-rank coal by the five power generation companies, and the trend is expected to accelerate further if the coal-fired flexible operation technology is applied to cope with the expansion of renewable energy. Various technologies such as electrostatic separation, gravity separation, bubble flotation, and oil agglomeration were presented through previous research in order to separate unburned coal ash (Lu et al., 2019), but no case has been applied to the site of coal-fired power plants. On the other hand, although there are various factors that cause the spontaneous combustion of coal in coal yards of coal-fired power plants (Zhilin et al., 2019; Ting et al., 2005), spontaneous combustion occurs mainly through the process of heat generated by contact between the surface of coal particles and oxygen in the atmosphere, and the heat accumulates inside the coal stockpile. Spontaneous combustion of coal at coal yards not only causes fuel loss, but also causes harmful substances such as volatile organic compounds (VOCs) and polycyclic aromatic hydrocarbons (PAHs) to be emitted to the environment during spontaneous combustion (Zhilin et al., 2017; Zhilin et al., 2016; Zhengyan et al., 2018; Deming et al., 2014). Previous studies suggest various methods to prevent spontaneous combustion, but most of them are based on the principle of preventing coal from contacting oxygen in the atmosphere by 
attaching spontaneous combustion inhibitor agents to the surface of coal particles (Xu et al., 2000; Zhilin et al., 2019; Yongliang et al., 2014; Zhengyan et al., 2018; Mao et al., 2010; Deming et al., 2014). However, since it is practically impossible to evenly attach spontaneous combustion inhibitors to the surface of coal particles, this method has few cases actually applied to coal yard sites at coal-fired power plants because the anti-ignition effect is not uniform and has local shortcomings. Therefore, in this study, the basic properties of high carbon ash for use as the main raw material for spontaneous combustion inhibitor were reviewed, and the results of the field demonstration of coal yard in coal-fired power plants were reviewed after manufacturing spontaneous combustion inhibitors with asphalt and PFAD.

\section{Material and Methods}

\subsection{Theoretical Background}

\subsubsection{Evaluation of kinetic parameters}

In order to identify the combustion mechanism and Kinetics of most fossil fuels, thermal decomposition and oxidation tests of char are essential, such as measurement of activated energy. Therefore, TGA/DTA is mainly used as a device to obtain Kinetics by continuously measuring mass as a function of temperature and time. The method of analysis of reaction velocity using TGA/DTA can be largely divided into isothermal method and nonisothermal method, and the non-isothermal method is again divided into differential method and integral method. The non-isothermal method has the advantage of being able to obtain characteristic values from a small number of experimental values and all temperature areas, and can also be tested if the samples are in exothermic reaction, and the disadvantage is that the characteristics such as activation energy and reaction order are uncertain. In general, the Conversion rate relates to the concentration and velocity constant of the reactant at a given temperature and may be indicated as follows.

$\frac{d x}{d t}=k(1-X)^{n}$ 
Here, $k$ means the reaction velocity and $n$ means the reaction order, so the temperature dependence of the reaction velocity is expressed as follows in Arrhenius.

$k=A \exp (-E / R T)$

Where $A$ stands for the reaction velocity, $E$ for the activation energy, $R$ for the gas constant and $T$ for the absolute temperature. The following equation can be obtained by organizing the above Eq. (1) and (2).

$\frac{d x}{d t}=A(1-X)^{n} \exp (-E / R T)$

In this study, the evaluation of kinetic parameters was performed using the result of non-isothermal thermogravimetric analysis using Coats-Redfern method (Coats et al., 1964), which provides activation energy, frequency factor and reaction order based on Eq. (3). Coats-Redfern method can be applied to a single heating rate condition and is mainly used for the evaluation of kinetic parameters of the non-isothermal combustion process and can be expressed as follows.

$\ln \left[g(\alpha) / T^{2}\right]=\ln \ln [A R / \beta E(1-2 R T / E)]-E / R T$

When assuming 2RT/E as 0 in Eq. (4) (Charles, 1965), it can be simplified as follows.

$\left.\ln \left[g(\alpha) / T^{2}\right]=\ln \ln [A R / \beta E)\right]-E / R T$

As a function of the conversion rate, Eq. (5) can be expressed as follows, depending on whether the reaction order is 1 and not 1 .

$n=1, g(\alpha)=-\ln (1-\alpha)$ 
$n \neq 1, g(\alpha)=\left[1-(1-\alpha)^{1-n}\right] /(1-n)$

\subsubsection{Contact angle}

The principle in which contact angles are formed is that there is a force to lower the energy in the plane, which is commonly referred to as the surface tension of the liquid, especially between the liquid and the gas.

Fig. 1 Basic concept of contact angle

$S, L$ and $G$ of Fig. 1 respectively refer to solids, liquids and gases, and the direction pointed by the arrow is the direction in which the surfactant forces are applied, i.e. the direction in which the surfactant energy is lowered. There are three interface sections where the force of tension in all of these steps is exerted in a way that reduces the area of each of them. And the part where these three sides meet is called the contact line. If the right-hand force is assumed to be + and the force equilibrium is set in a horizontal direction, it can be expressed as shown in Eq. (8).

$F=Y_{S G}-Y_{S L}-Y_{L G} \times \cos \cos \theta_{C}=0$

The above equation is called Young's equation, and the contact angle that makes the above equation is called the equilibrium contact angle, which is one of the important characteristics of the solid surface. Usually, the term contact angle is used to refer to this equilibrium contact angle. Young's equation is not equation for all contact angles. If the current contact angle $\theta$ is larger than the equilibrium contact angle $\theta_{C}$, the above equation can be expressed as follows.

$F=Y_{S G}-Y_{S L}-Y_{L G} \times \cos \cos \theta_{C}>0$

The contact line is subjected to an outward force of $F$, which spreads until $\theta$ is as small as $\theta_{C}$. This force $F$ is called uncompensated Young's force, and the presence of this force caused the liquid to move to its own 
equilibrium contact angle under any circumstances. At this time, if this equilibrium contact angle is less than $90^{\circ}$, it is called hydrophilic surface, and if it is more than $90^{\circ}$, it is called hydrophobic surface. Naturally, these contact angles vary depending on the liquid used, which is called an oleophilic surface when the liquid is of an oil type and the equilibrium contact angle is below $90^{\circ}$, and an oleophobic surface when the equilibrium contact angle is above $90^{\circ}$. In real situations, the equilibrium contact angle is often not achieved because the surface is not completely flat and rough, or because of the presence of chemical imbalance on the surface ( $Y S G$ is uneven), which is called the contact angle hysteresis.

\subsubsection{Hardness}

The general concept of hardness is based on the experience of being soft, hard, and the most common definition cab be expressed as the local resistance that the material represents when a certain object is pressed into the surface of the material with a constant load. Hardness is not a physical constant directly related to the physical properties, but an artificially determined industrial constant that is used to estimate strength from the hardness value, or to compare the status of the specimen from the hardness value after processing or heat treatment. Hardness test is a non-destructive material test, which has the advantage of being able to quickly obtain results that are very simple, objective and reproducible. It can be applied to a wide range of materials and sample, and is a standard and representative value of typical properties of materials. Hardness is largely divided into pressing, dynamic and thickness, and is classified as Table 1 according to the test method.

Table 1 Classification of hardness measurement method

\subsubsection{Viscosity}

Viscosity means internal friction or resistance that occurs when a fluid (gas or liquid) flow. Fluid flowing evenly along a surface have the fastest speed in the center and the slowest near the surface, due to friction between solid surfaces and fluids. Friction with the surface causes the near-fluid layers to flow more slowly. Viscosity is one of the very important properties of the fluid. Viscosity is very important when dealing with oils and organic liquids, 
as industrially heavy oils and liquids have low densities but very high viscosity. The unit of viscosity is poise (cgs unit system), which is equal to $1 \mathrm{~g} / \mathrm{cm} \cdot \mathrm{s}$, and $\mathrm{cP}$ (centi-poise) is generally used. The available viscosity measurement methods vary depending on the viscosity range and the characteristics of the liquid.

\subsection{Collection of high carbon ash samples and selection of raw materials for spontaneous combustion inhibitor}

As raw materials for the manufacture of spontaneous combustion inhibitor in this study, high carbon ash and as petroleum-based compounds, asphalt and PFAD (palm fatty acid distillate) were used. High carbon ash is known to be caused by excessive blending of low combustible coal and imbalance in the combustion environment in the furnace (Bora et al., 2010; McHahan et al., 2002), and the proportion of high carbon ash produced at domestic coal-fired power plants is about $15.0 \%$ to $23.6 \%$ (' 16 to ' 18 ) based on the total amount of coal ash and showing an increasing trend. In this study, 10 coal-fired power plants in Korea were selected, and fly ash, bottom ash and pond ash were collected respectively. In the case of fly ash, the samples were collected immediately after the production, and the bottom ash and pond ash were collected at ash ponds by selecting the sampling points with less impact of seawater. Samples collected were measured in accordance with the Korean Standard for Quality (KS L 5405) and used as target samples for this study if the unburned carbon content was more than 5\%. The collection of high carbon ash is as shown in Fig. 2.

Fig. 2 Collection of high carbon ash

Asphalt refers to the final residue after hard oil is removed from crude oil, and is divided into native asphalt and petroleum asphalt, which is obtained after refining crude oil. Native asphalt can range from asphalt that contains little mineral matter to rock asphalt, which is low in asphalt content. In general, native asphalt which has the high melting point and little mineral contents is called asphatite and asphalt containing minerals such as sand, sandstone, limestone and etc. is called rock asphalt. Petroleum asphalt is recognized as having the same properties as native asphalt as residue obtained after the distillation of crude oil around 1880, which is said to be petroleum asphalt, distinct from native asphalt. The most important factor in determining the quality of asphalt is the type of crude oil, which varies in composition depending on paraffin, naphthene and mixed crude oil. Crude oil contains oxygen, 
nitrogen and sulfur compounds in addition to hydrocarbons, producing asphalt with various characteristics depending on the composition and manufacturing method of crude oil. The main components of asphalt are various hydrocarbons with an average molecular weight of about 500 to 2,000 and asphalt can be divided into asphaltene, resin and oil, and is composed of sulfur, nitrogen, oxygen and small amount of metallic compounds. Asphalt has the characteristics of high adhesion, plasticity, water resistance and electrical properties, so it has various uses such as road pavement, waterproof materials and adhesives. Typical element composition of asphalt is as shown in Table 2.

Table 2 Element composition of asphalt

Various products are produced in the refining process of palm, mainly palm oil, palm olein, palm stearin, palm kernel, palm kernel olein and palm kernel stearin. Among them, palm fatty acid distillate (PFAD) is a byproduct of palm oil refining and is obtained from the distillate of the stripping tower of free fatty acid (FFA). The main ingredient of palm oil is oleic acid, stearic acid and palmitic fatty acids, which are used in many industries such as soap industry, animal food industry, and are also used as raw materials for bio-diesel and chemical industry.

\section{Results and discussion}

\subsection{Proximate and ultimate analysis of high carbon ash}

As a result of proximate and ultimate analysis by selecting coal ash with an unburned carbon content of $5 \%$ or more, the amount of unburned carbon was relatively high in the case of pond ash, and collecting ash samples at ash ponds resulted in high moisture and oxygen content. Most of heating values were very low, below 1,340 $\mathrm{kcal} / \mathrm{kg}$, and the combustion of high carbon ash with unburned carbon content under $10 \%$ was impossible, so no higher or lower heating values were obtained.

Table 3 Proximate analysis and unburned carbon contents of high carbon ash

Table 4 Ultimate analysis of high carbon ash 


\subsection{Heat transfer characteristics}

Since the spontaneous combustion inhibitor of this study is applied to the surface of the coal stockpile, it is necessary to look at what role it plays in the heat exchange process inside and outside of the coal stockpile. The thermal diffusivity, conductivity and specific heat at constant pressure were measured at three temperatures $\left(25^{\circ} \mathrm{C}\right.$, $100^{\circ} \mathrm{C}$ and $300^{\circ} \mathrm{C}$ ) to identify the heat transfer characteristics of 10 high carbon ash, and the thermal diffusivity, conductivity and specific heat at constant pressure values at $300^{\circ} \mathrm{C}$ were not significantly different from sample to sample, and show relatively significant differences at $25^{\circ} \mathrm{C}$ and $100^{\circ} \mathrm{C}$. If we look at the heat transfer characteristics by type of coal ash (fly ash, bottom ash and pond ash), overall, diffusivity, conductivity and specific heat at constant pressure values of fly ash were the lowest compared to bottom ash and pond ash. The mean value of specific heat at constant pressure of fly ash was the lowest at $0.69 \mathrm{~J} / \mathrm{g} / \mathrm{K}$ at $25^{\circ} \mathrm{C}, 0.92 \mathrm{~J} / \mathrm{g} / \mathrm{K}$ at $100^{\circ} \mathrm{C}$, and the pond ash was found to be $1.30 \mathrm{~J} / \mathrm{g} / \mathrm{K}$ at $25^{\circ} \mathrm{C}, 2.77 \mathrm{~J} / \mathrm{g} / \mathrm{K}$ at $100^{\circ} \mathrm{C}$. In the case of conductivity, bottom ash and pond ash were similar levels, but the fly ash was the lowest at $25^{\circ} \mathrm{C}$ to $0.06 \mathrm{~W} / \mathrm{m} \cdot \mathrm{K}$, and $0.07 \mathrm{~W} / \mathrm{m} \cdot \mathrm{K}$ at $100^{\circ} \mathrm{C}$, but similar to conductivity values at $25^{\circ} \mathrm{C}$ and $100^{\circ} \mathrm{C}$ of the sub-bituminous (flame) coal. In particular, if we look at the relationship between unburned carbon content and heat transfer characteristic coefficients, the higher unburned carbon content, the higher diffusivity $\left(\mathrm{R}_{2}=0.72 \sim 0.98\right)$, the higher conductivity $\left(\mathrm{R}_{2}=0.81 \sim 1.00\right)$ and the higher specific heat at constant pressure $\left(\mathrm{R}_{2}=0.69 \sim 0.96\right)$ in bottom ash and pond ash, and the coefficient of determination between unburned carbon content and conductivity of fly ash was 0.38 to 0.55 , and -0.47 to -0.63 between unburned carbon content and specific heat at constant pressure, so it was found the higher unburned carbon content in fly ash, the lower specific heat at constant pressure value. Considering the characteristics of spontaneous combustion inhibitor of this study applied to the surface of coal stockpiles and the mechanism for accelerating spontaneous combustion by thermal accumulation inside the coal stockpile, it was predicted that fly ash with high unburned carbon content would be relative easy to dissipate heat inside coal stockpile to the outside. In fact, spontaneous combustion tends to occur frequently at points about 1.0 to 1.5 meters deep from the surface of the coal stockpiles. In the case of the surface of coal stockpile, coal particles have a high frequency of contact with the outside air, but can easily release the oxidative heat generated by low-temperature oxidation, so it does not proceed until spontaneous combustion, but deeper points accumulate inside with emitting heat to the outside. Therefore, fly ash, which is relatively good heat transfer characteristics and is easy to release internal heat of coal 
stockpile to the outside, is believed to be more suitable as a raw material for spontaneous combustion inhibitor.

Table 5 Diffusivity, conductivity and specific heat at constant pressure of high carbon ash

Fig. 3 The relationship between unburned carbon content and heat transfer characteristics by types of coal ash

\subsection{Scanning electron microscope (SEM) and energy dispersive X-ray spectrometer (EDS) analysis}

Fly ash among the coal ash generated from coal-fired power plants is known to be mainly generated in spherical form. However, as shown in Fig. 4 (a), the combustion takes place by repeating the process of expansion, contraction and explosion of the coal char, which is emitted as it is not fully burned during the expansion process, resulting in the form of porosity. On the other hand, in this study, high carbon ash could be found in the form of a plerosphere with a large mass of unburned carbon, ash show in Fig. 4 (b). It was predicted that the re-combustibility of unburned carbon would be excellent if it was porous, but the re-combustibility would be relatively low if it was in the form of plerosphere. An EDS analysis of the coal ash in Fig. 5 shows that there is a significant amount of unburned carbon, in spite of most of the composition of $\mathrm{Si}$, as shown in Fig. 5.

Fig. 4 SEM picture of high carbon ash

Fig. 5 Graph of EDS analysis for high carbon ash

\subsection{Variation of unburned carbon content by coal particle size}

Most electrostatic precipitator (ESP) that collect fly ash are composed of 5 layers, and in the case of the first stage, relatively coarse particles and collected, and the later they collected, the finer fly ash is collected. In order to examine the variation of unburned carbon content by ESP layers and ash particle size, the first and second stage of ESP in operation at three coal-fired power plants were collected, and the first to the fourth stage of the ESP were collected separately for one coal-fired power plants. After dividing the collected fly ash samples into 7 groups by particle size using standard sieves and examining the unburned carbon content, as shown in Fig. 6 (a), the 
unburned carbon content is $36.80 \sim 62.20 \%$ in the case of particle size with more than $150 \mathrm{um}, 25.02 \sim 46.30 \%$ in the range of 105 150um, 10.69 32.20\% in the range of 74 105um, which means the coarser particles have higher unburned carbon content than finer particles. On the other hand, the means value of the unburned carbon content in fine particle with less than 53um was between 3.37 and 5.98\%. In the case of 1S-A2, 1T-A2 and 5T-A3 samples, the mean value of unburned carbon content exceeded 5\%, but the remaining seven samples were found to be below $5 \%$, so even if they were high carbon ashes, fine particles could be recycled as cement concrete mixtures as usual through separation by particle size and coarse particles could be used as a raw material of spontaneous combustion inhibitor to prevent fuel loss. Even if particle size is with the same range, samples collected from the rear of ESP were found to have a relatively slightly higher unburned carbon content, but the difference was not significant.

Fig. 6 Unburned carbon content of fly ash by ESP layers and particle size

\subsection{Thermogravimetric analysis and evaluation of kinetic parameters for high carbon ash}

Since high carbon ash which is used as a raw material of spontaneous combustion inhibitor is applied to the surface of coal stockpiles and then re-burned in the boiler with coal after a certain period of time has elapsed, recombustibility is important factor to be considered to use as a raw material for spontaneous combustion inhibitor. Because high carbon ash is burned once in a high temperature boiler in the rage of about $1,200 \sim 1,400^{\circ} \mathrm{C}$, it is expected to be difficult to re-burn it due to its low volatile matter content and incompletely burned characteristic. The characteristics of combustion were identified by thermogravimetric analysis (TGA) for fly ash and bottom ash among 10 type of high carbon ash of this study and compared them with the results of the design coals (Flame and Anglo) of coal-fired power plant. Using the STA-1000 model of Lineseis Co. as thermogravimetric analyzer, the combustion profile of high carbon ash and design coal was obtained, and the thermogravimetric analysis was conducted under non-isothermal condition with heating rate of $10^{\circ} \mathrm{C} / \mathrm{min}$ in air mood. As in Fig. 7 (a), it was found that the burning of high carbon ash was initiated at a temperature of about 500 to $600^{\circ} \mathrm{C}$, which is relatively higher than that of Flame coal, excluding dehydration reaction, and burned to over $800^{\circ} \mathrm{C}$. Flame coal, on the other hand, showed the characteristics of combustion being completed around $600^{\circ} \mathrm{C}$. Similar characteristics were shown in the bottom ash, as combustion began in high temperature areas near about 500 to $600^{\circ} \mathrm{C}$ and combustion was completed at about $850^{\circ} \mathrm{C}$ or higher, indicating that high carbon ash continued to be burned even within the 
temperature range where combustion of the design coal is completed.

Fig. 7 Thermogravimetric analysis for high carbon ash

In order to examine the detailed combustion profile of high carbon ash, an investigation of Arrhenius parameter is required. Using Coats-Redfern method, Arrhenius parameters were calculated and compared with two types of design coal, and found that the activation energy of high carbon ash (fly ash, bottom ash and pond ash) was higher than that of the design coals and the frequency factor was lower. In particular, the activation energy of fly ash was higher than that of bottom ash and pond ash, so resulting in low re-combustibility of fly ash. This characteristic is supported by that the unburned carbon content of bottom ash and pond ash is relatively higher than that of fly ash, and some bottom ash have shown similar levels of activation energy and frequency factor. Therefore, although the re-combustibility of bottom ash is relatively superior to that of fly ash, it was judged that it would be necessary to control the particle size through differentiation in order to use it as a raw material of spontaneous combustion inhibitor.

Fig. 8 Arrhenius plot for high carbon ash

Table 6 Activation energy and frequency factor for high carbon ash

\subsection{Contact angle of spontaneous combustion inhibitor}

The measurement of contact angle was conducted using Biolin Scientific Co.'s Attension Thema Lite model. The baseline was automatic for measuring contact angle, both analysis mode and secondary analysis mode was contact angle (Young-Laplace). When manufacturing the specimen, the surface was flattened and smoothed, then the droplet was dropped in a sessil drop, then the contact angle was measured at 3.0s at 10\% (7.6 frame per second) and their average values were used. As a result of measuring the contact angles by measuring temperature and mixing ratio of high carbon ash, asphalt and PFAD which are raw materials for spontaneous combustion inhibitor, contact angles were more than $90^{\circ}$ in case of room temperature, which means the characteristic of hydrophobic surface is maintained regardless of the mixing ratio of raw materials. If the mixing ratio of asphalt and PFAD is 
5:1 to 3 , the contact angle tends to increase slightly when the mixing ratio of ash increase, and if the mixing ratio of asphalt and PFAD is 7:1, the contact angle decrease slightly when the mixing ratio of ash increase, but this is not considered significant. The contact angle in the heated condition was measured immediately after dropping water droplet on the sample's surface in the measuring chamber under harsh temperature condition significantly higher than the nation's summer peak temperature $\left(40^{\circ} \mathrm{C}\right.$, Daegu metropolitan city on 1st August, 1942). In the case of heated condition, the contact angles decrease as the ratio of PFAD to asphalt increases. Figures show that the surface characteristics change from hydrophobic to hydrophilic, but it was judged to the surface of spontaneous combustion inhibitor changes to liquid in the range of about 65 to $70^{\circ} \mathrm{C}$ in the chamber temperature as PFAD is melted near about $50^{\circ}$.

Fig. 9 Contact angle by measuring temperature and mixing ratio of raw materials

\subsection{Hardness of spontaneous combustion inhibitor}

A portable hardness measuring device was used to measure the hardness of spontaneous combustion inhibitor. As the hardness of the specimen was not expected to be not high in spite of room temperature immediately after mixing raw materials due to the characteristics of the raw materials and mixing ratio conditions, the test piece surface of the hardness measuring device was flat. The spontaneous combustion inhibitor contained in the container was kept at room temperature and pre-set temperature for a certain period of time, then the hardness measuring device was vertical and pressed until the test piece reach a certain depth, and the maximum peak value of the hardness was used. As a result of hardness characteristics evaluation for spontaneous combustion inhibitor by mixing ratio of raw materials, the hardness level increase as the mixing ratio of ash increases. In particular, this tendency was noticeable in the case of room temperature, and the tendency of increase in hardness by coal ash was somewhat reduced when the mixture ratio of PFAD was increase. In addition, the hardness level was found to be lower than the room temperature overall when the temperature condition was $50^{\circ} \mathrm{C}$. When the mixing ratio was $7: 1: 28$, the hardness exceeded the upper measurement limit of the device $(200 \mathrm{~N})$ for both room temperature and $50^{\circ} \mathrm{C}$. As a result of measuring hardness value with setting higher temperature condition, when the mixing ratio of asphalt and PFAD was between $5: 1$ to 3 , the hardness was drastically reduced compared to $50^{\circ} \mathrm{C}$ when the measured temperature was over $100^{\circ} \mathrm{C}$. Similar trends were found in the case of the mixing asphalt and PFAD 
with the ratio of $7: 1$, but the increase of the mixing ratio of coal ash resulted in a significant decrease in that trend.

Fig. 10 Hardness by measured temperature and mixing ratio of raw materials

\subsection{Viscosity of spontaneous combustion inhibitor}

In this study, viscosity was measured using Rotating Concentric-Cylinder Viscometer. The viscosity was measured by heating the spontaneous combustion inhibitor contained in the container to a pre-set temperature and having the horizontal plane of the viscometer spindle reach a constant depth, and rotating the spindle. The viscosity of spontaneous combustion inhibitor by temperature and mixing ratio of raw materials is expected to be measured in various range, so the spindle of the form that can contain the largest range of viscosity is used as the bases, and if it is outside the measure range, the spindle should be changed to match the corresponding viscosity. In the case of mixing ratio of asphalt and PFAD with 5:1 to 3, it can be seen that the viscosity of spontaneous combustion inhibitor decreases as the mixing ratio of PFAD increase. In addition, regardless of the mixing ratio, the viscosity was reduced when the temperature increased, and under the same temperature condition, the viscosity of spontaneous combustion inhibitor increased when the mixing ratio of coal ash increased. Samples of which mixing ratio of asphalt, PFAD and high carbon ash with 5:3:5 are those with the highest mixing ratio of PFAD and the lowest mixing ration with high carbon ash, and the viscosity of this specimen was found to be similar to liquid at $90^{\circ} \mathrm{C}$ and outside the lower measure limit of the viscometer. In the case of samples with mixing ratio of 7:1:28, viscosity measurement was not possible regardless of temperature, because there was space between the spindle of the viscometer and the sample, so adhesion was not generated.

Fig. 11 Viscosity by measured temperature and mixing ratio of raw materials

\subsection{Verification of the effect of preventing spontaneous combustion in coal yard of coal-fired power plant}

Considering the characteristics of high carbon ash, which was investigated as above, to be applied as a raw material of spontaneous combustion inhibitor and contact angle, viscosity and hardness of spontaneous combustion inhibitor, the spontaneous combustion inhibitor was manufactured and applied to the coal yard of coal-fired power 
plant to verify the effect of preventing spontaneous combustion at the site. Bayon coal was selected as target coal, a sub-bituminous coal with frequent spontaneous combustion, and thermocouples were installed by the location and depth from the surface of coal stockpile, such as Fig. 12. Afterwards, spontaneous combustion inhibitor was applied to the surface area of the coal stockpile and temperature data was obtained over time. Spontaneous combustion occurs mainly in the lower part of coal stockpile, because the coarse coal particle is mainly located in the lower part of the stockpile in the process of coal being stored in coal yard, resulting in a relatively large void in the lower part of the coal stockpile, which increases the possibility of coal particles contacting oxygen in the outside air. Therefore, spontaneous combustion inhibitors were applied mainly to the lower part of the coal stockpile.

Fig. 12 Conceptual diagram of applying spontaneous combustion inhibitor and coal stockpile in coal yard

The temperature changes of coal stockpile according to the application of spontaneous combustion inhibitor, such as Fig. 13, showed a relatively large difference. When spontaneous combustion inhibitor was not applied, the maximum of the instantaneous increasing rate of temperature per minute was $1.60^{\circ} \mathrm{C} / \mathrm{min}$ at the point of $\mathrm{C} 8-2$, while it was lowered to $0.061{ }^{\circ} \mathrm{C} / \mathrm{min}$ at the point of $\mathrm{C} 5-2$ after applying spontaneous combustion inhibitor. The instantaneous increasing rate of temperature in coal stockpile is an important factor in the progress of spontaneous combustion, and the heat tends to accumulate inside as the internal temperature of the coal stockpile fluctuates according the changes in external temperature. Since spontaneous combustion generally begins at a time when the internal temperature of coal stockpile exceeds a certain level and the instantaneous increasing rate of temperature rises sharply, even if the internal temperature of coal stockpile is high, the occurrence of spontaneous combustion can be delayed when the instantaneous increasing rate of temperature is low. On the other hand, if we look into the changes in the temperature of coal stockpile for the entire period of the site demonstration, the temperature of coal stockpile does not exceed a certain level from about $40^{\circ} \mathrm{C}$ which is the initial temperature, while if the spontaneous combustion inhibitor is not applied, the heat accumulates inside the coal stockpile from the beginning stage at the coal yard, causing spontaneous combustion to occur around 20 days later. In conclusion, it was judged that the manufacture of spontaneous combustion inhibitor using high carbon ash and application to the coal stockpile surface area blocked the contact between coal particle and external air, which had the effect of preventing spontaneous combustion in both terms of instantaneous increasing rate of temperature and internal temperature 
change at the coal yard, and that it was proven to be substantially at the site of coal yard in coal-fired power plants.

Fig. 13 Comparison of temperature change and instantaneous increasing rate of temperature by application of spontaneous combustion inhibitor

\section{Conclusion}

In this study, physical-chemical properties, fuel characteristics and combustibility of high carbon ash for use as a raw material for spontaneous combustion inhibitor at coal yard of coal-fired power plants in Korea were examined. In addition, the following results could be obtained by demonstrating the spontaneous combustion inhibitor manufactured using high carbon ash, asphalt and PFAD at coal yard of coal-fired power plants.

(1) The unburned carbon content of high carbon ash in this study was very high at 12.41 to 24.70 , and the heating value was in the range of 710 to $1,340 \mathrm{kcal} / \mathrm{kg}$. The results of the combustibility evaluation showed that the activation energy was $18.944 \mathrm{~kJ} / \mathrm{mol}$ of bituminous coal, $85.952 \mathrm{~kJ} / \mathrm{mol}$ of fly ash average, $38.909 \mathrm{~kJ} / \mathrm{mol}$ of bottom ash average, and the frequency factor was $91,419 \mathrm{~s}-1$, fly ash average of 43,493 s-1, and bottom ash average of 124,834 s-1. In the case of high carbon ash, the re-combustion activation energy and the frequency factor are similar to bituminous coal and the combustion reactivity are good in porous unburned carbon exists.

(2) As a result of examining the thermal diffusivity, conductivity and specific heat at constant pressure as heat transfer characteristics of high carbon ash, fly ash is the lowest overall than the bottom and pond ash. When looking into the relationship between the unburned carbon content and the heat transfer characteristic coefficients, the higher the unburned carbon content, the higher the thermal diffusivity ( $\mathrm{R}_{2}=0.72 \sim 0.98$ ), conductivity $\left(\mathrm{R}_{2}=0.81 \sim 1.00\right)$, and specific heat at constant pressure $\left(\mathrm{R}_{2}=0.69 \sim 0.96\right)$. In the case of fly ash, the higher the unburned carbon content, the lower the specific heat at constant pressure value, and it was judged that fly ash, which has relatively good heat transfer characteristics, would be more suitable for releasing the internal heat of coal stockpile to be applied as a raw material for spontaneous combustion inhibitor.

(3) Looking into the unburned carbon content of fly ash by collecting layers of ESP, coarse fly ash with particle size of more than 74um has unburned carbon content of $10.69 \sim 62.20 \%$, which is much higher than fine 
particles, and fine fly ash with particle size of less than 53um has unburned carbon content of 5\% or less, except in some cases. Therefore, it was deemed possible to prevent fuel loss by separating high carbon ash by particle size and recycling fine particle as a concrete mixture as before, and re-burning coarse particle by using it as a raw material for spontaneous combustion inhibitor.

(4) As a result of thermogravimetric analysis of high carbon ash, it was found that combustion began near 500 to $600^{\circ} \mathrm{C}$, which is relatively higher than the combustion temperature of bituminous coal, and the combustion was carried out to about $800^{\circ} \mathrm{C}$. Arrhenius parameters were calculated using Coats-Redfern method, and the activation energy was higher than design coal and the frequency factor was lower than design coal. The combustion characteristics of bottom ash and pond ash were relatively good compared to fly ash due to their higher unburned carbon content and it was judged it would be necessary to adjust the particle size through pulverization or separation in order to use them as raw materials for spontaneous combustion inhibitor.

(5) As a result of examining the contact angle for water, hardness and viscosity of spontaneous combustion inhibitor manufactured by mixing high carbon ash, asphalt and PFAD, the contact angle for water, regardless of the mixing ratio, was found to be more than $90^{\circ}$, maintain the hydrophobic characteristics of the surface. As the ratio of asphalt and PFAD mixture increased, the contact angle increase slightly, and the hardness level increase as the ratio of high carbon increased. After a certain period of time after mixing the raw materials of spontaneous combustion inhibitor, the hardness level exceeded the upper measurement limit. Meanwhile, in the case of viscosity, the viscosity of spontaneous combustion inhibitor was reduced as the ratio of asphalt and PFAD mixture increased. The hardness and viscosity of spontaneous combustion inhibitor are conflicting characteristics, and low viscosity makes it easy to spray spontaneous combustion inhibitor, but the hardness can be lower after being applied to coal stockpiles, so hardness and viscosity will be considered important factors in deriving the optimal mixing ratio suitable for coal yard at coal-fired power plants.

(6) As a result of applying the spontaneous combustion inhibitor in this study to coal stockpiles in coal yard of coal-fired power plants, the highest value of instantaneous increasing rate of temperature was $1.60^{\circ} \mathrm{C} / \mathrm{min}$ without spontaneous combustion inhibitor applied, while it was very low to $0.061^{\circ} \mathrm{C} / \mathrm{min}$ when applied. The initial temperature of the coal stockpile subject to the demonstration was about $40^{\circ} \mathrm{C}$ and spontaneous combustion occurred about 20 days after storage if spontaneous combustion inhibitor was not applied, but 
when the spontaneous combustion inhibitor was applied, contact of the coal stockpile with the external air was blocked, which showed a significant effect of preventing spontaneous combustion

Overall, pulverization or separation process should be necessary to use high carbon ash as a raw material for spontaneous combustion inhibitor and it could accelerate the combustibility of spontaneous combustion inhibitor when highly combustible additive was selected, resulting in low possibility of unburned carbon emission.

\section{Authors' contribution}

Conceptualization, methodology, formal analysis and writing-original draft were carried out by Seok Un Park and validation, investigation, data curation, writing-review \& editing and supervision were carried out by Jae Kwan Kim.

\section{Availability of data and materials}

All the data has already included in manuscript.

\section{Compliance with ethical standard}

\section{Conflict of interest}

No conflict of interest exits in the submission of this manuscript, and manuscript is approved by all authors for publication.

\section{Acknowledgement}

This research was conducted through the support of the Korea Institute of Technology Evaluation and Planning’s 2014 Energy Technology Development Project (20141010101880).

\section{References}

Bora C, Ahmet HA, Yucel G (2010) Stabilization of recycled base materials with high carbon fly ash. Resour Conserv Recycl 54(11):878-892 
Charles DD (1965) Series approximations to the equation of thermogravimetric data. Nature 207:290-291

Coats AW, Redfern JP (1964) Kinetic parameters from thermogravimetric data. Nature 201:68-69

Deming W, Guolan D, Xiaoxing Z, Haihui X, Botao Q (2014) An experimental approach to selecting chemical inhibitors to retard the spontaneous combustion of coal. Fuel 117(A):218-223

Lu Y, Danlong L, Zhenna Z, Ming X, Xiaokang Y, Haijun Z (2019) Effect of the intensification of preconditioning on the separation of unburned carbon from coal fly ash. Fuel 242:174-183

Mao JD, Schimmeimann A, Mastalerz M, Hatcher PG, Li Y (2010) Structural feature of a bituminous coal and their changes during low-temperature oxidation and loss of volatiles investigated by advanced solid-state NMR spectroscopy. Energy fuels 24(4):2536-2544

McHahan LG, Kenneth JC, Yee S, Richard PK, Mercedes MV, John MA, Michael VC, Paul HZ (2002) Physical cleaning of high carbon fly ash. Fuel Process Technol 76(1):11-21

Ting S, Xiaofang W, Jun D, Zhenyi W (2005) The mechanism at the initial stage of the room-temperature oxidation of coal. Combust Flame 140:332-345

Xu JC, Guo XM, Deng J (2000) Technology of mine fire direct extinguishing with temperature resistance high water gel for seam fire. Int J Coal Sci Technol 28(3):4-6

Yaowen X, Fangyu G, Mengdi X, Xiahui G, Haisheng L, Guosheng L, Yangchao X, Haisheng H (2019) Separation of unburned carbon from coal fly ash: A review. Powder Technol 353:372-384

Yongliang Y, Zenghua L, Yibo T, Zhen L, Huaijun J (2014) Fine coal covering for preventing spontaneous combustion of coal pile. Nat Hazards 74(2):603-622

Zhengyan W, Shanshan H, Shuguang J, Xinjian H, Hao S, Kai W, Deqiang F, Wanrong L (2018) Experimental study on prevention and control of coal spontaneous combustion with heat control inhibitor. J Loss Prevent Proc 56:272-277

Zhilin X, Ding L, Zhenya F (2017) Characteristics of polymorphic foam for inhibiting spontaneous coal combustion. Fuel 206(15):334-341

Zhilin X, Xiaodong W, Xiaoli W, Li W, Ding L, Xiangyu G, Liwei J (2019) Polymorphic foam clay for inhibiting the spontaneous combustion of coal. Process Saf Environ 122:263-270

Zhilin X, Xutong S (2016) Effectiveness of thermoplastic powder to retard self-heating and spontaneous combustion of coal. Combust Sci Technol 188(8):1331-1344 


\section{Figures}

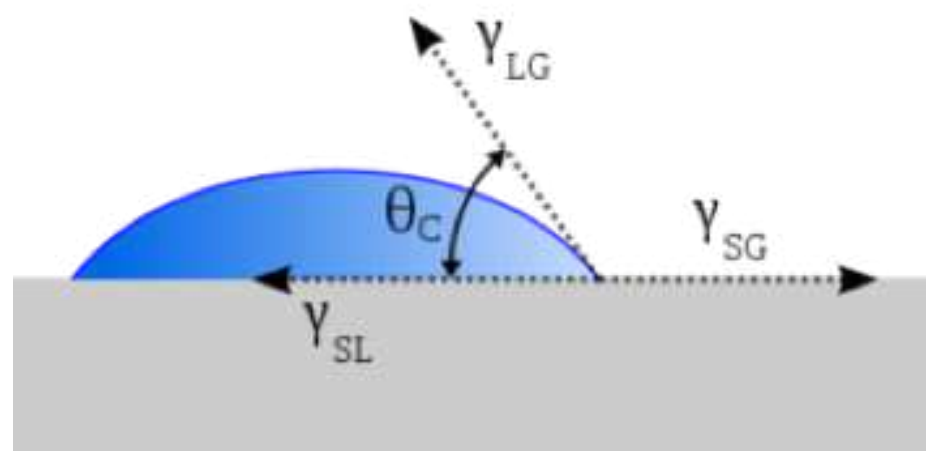

Figure 1

Basic concept of contact angle

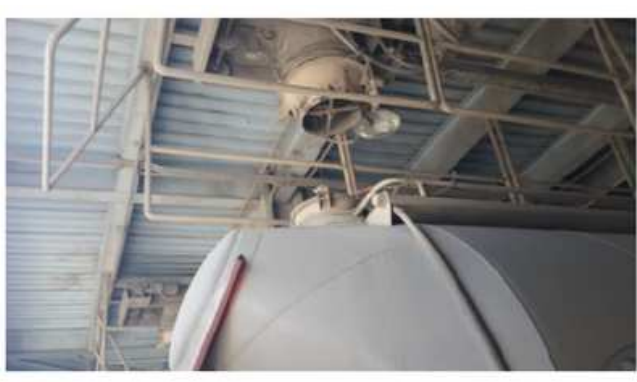

(a) Fly ash

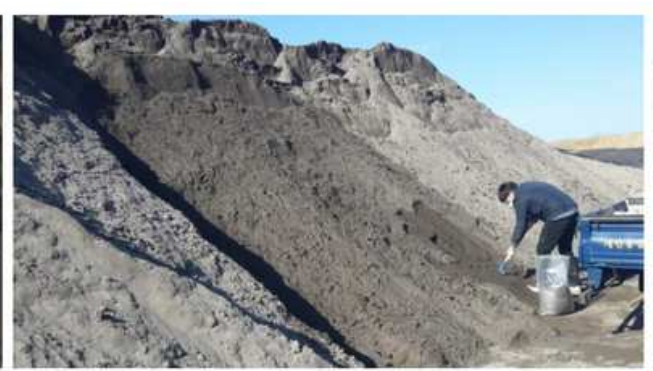

(b) Bottom ash

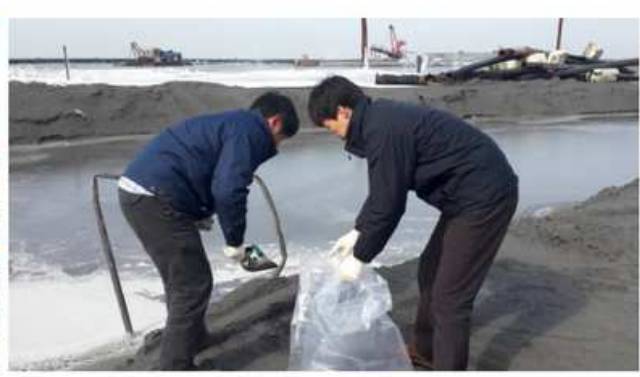

(c) Pond ash

Figure 2

Collection of high carbon ash 
Fly ash

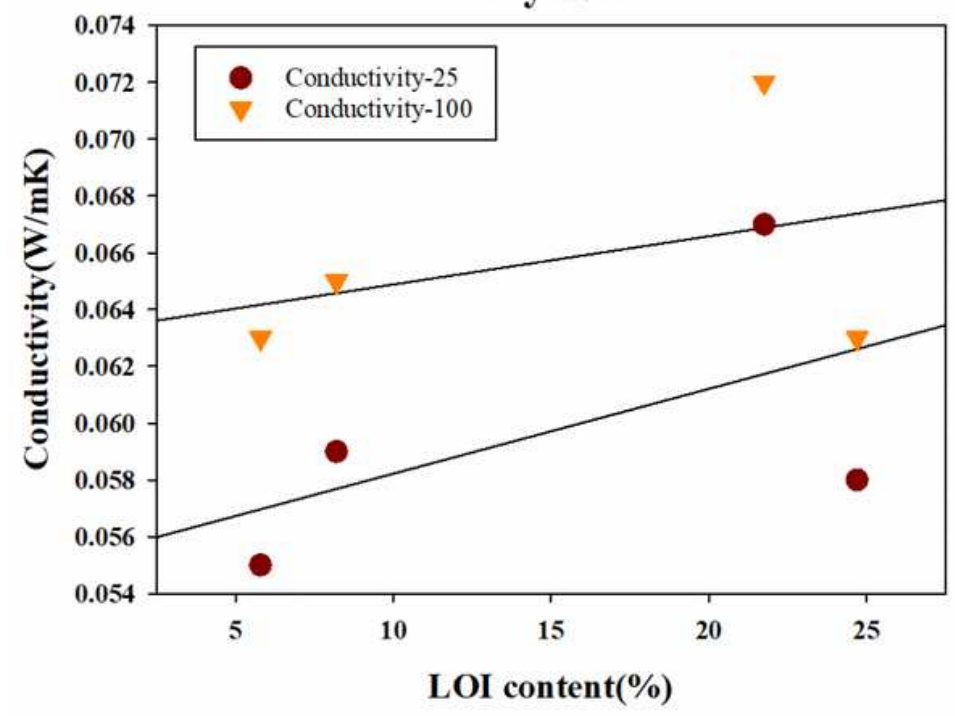

Fly ash

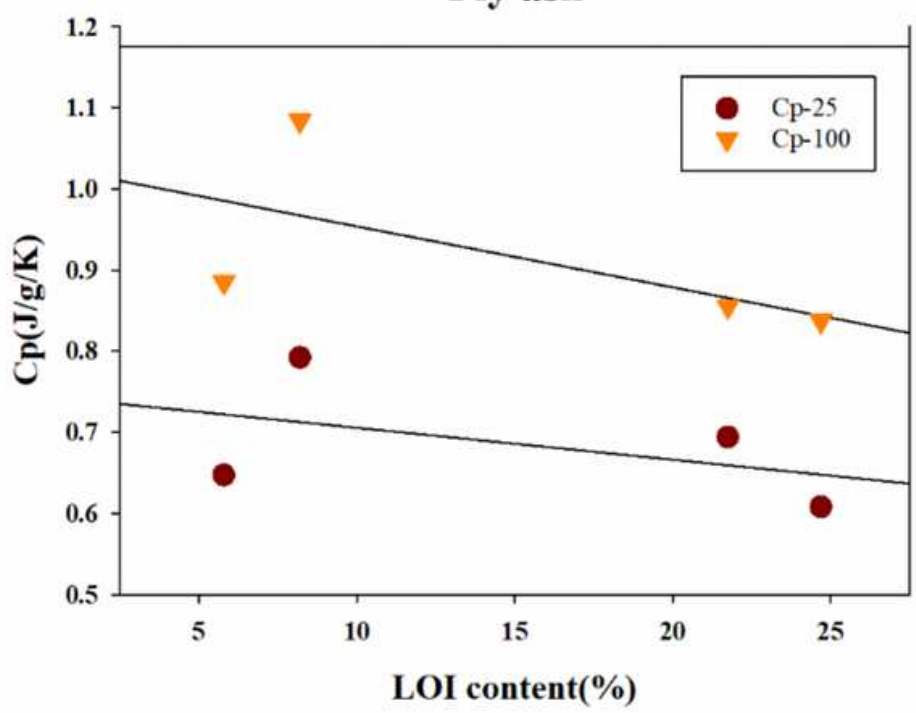

(a) Fly ash
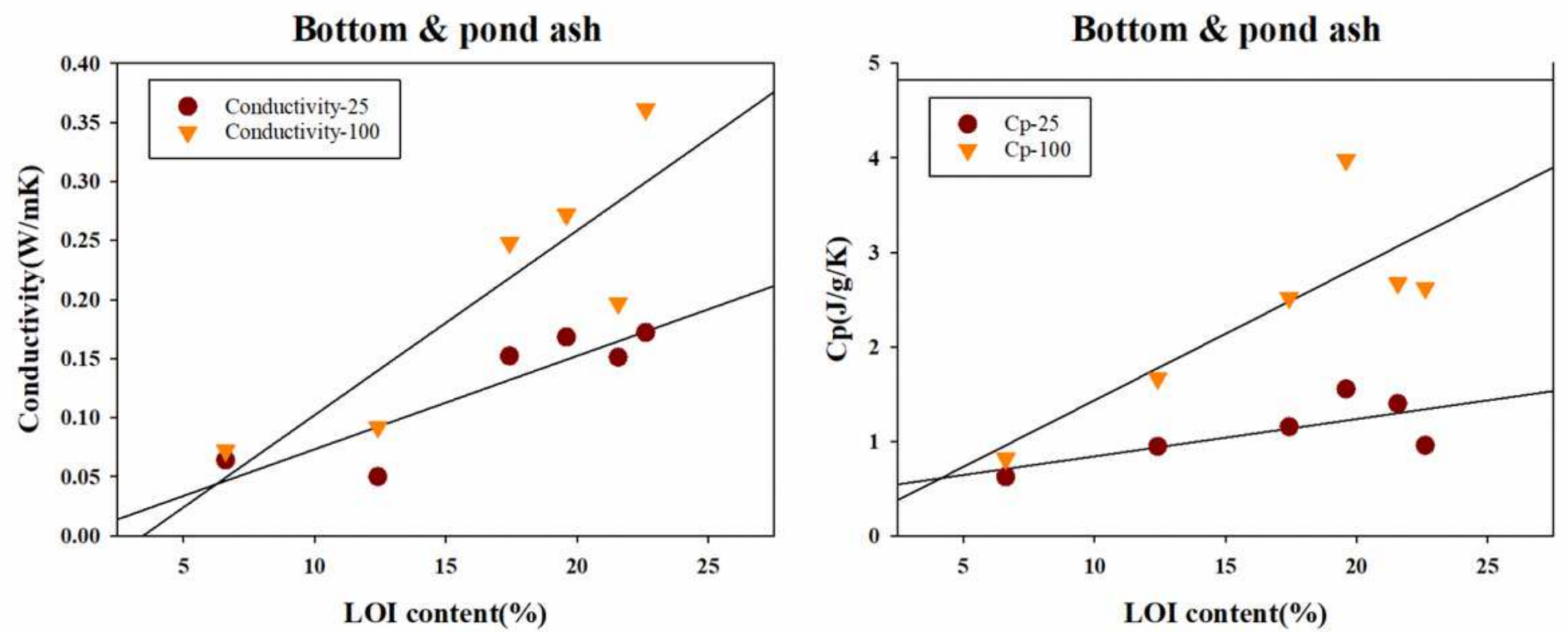

(b) Bottom ash and pond ash

\section{Figure 3}

The relationship between unburned carbon content and heat transfer characteristics by types of coal ash 


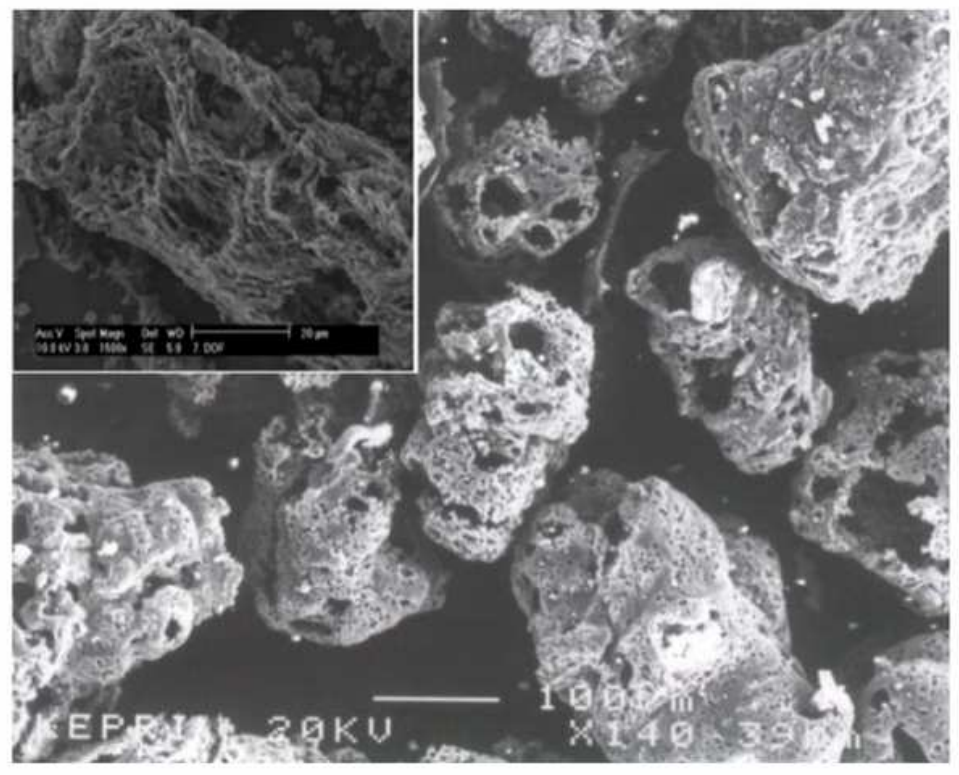

(a) Unburned carbon in porous form

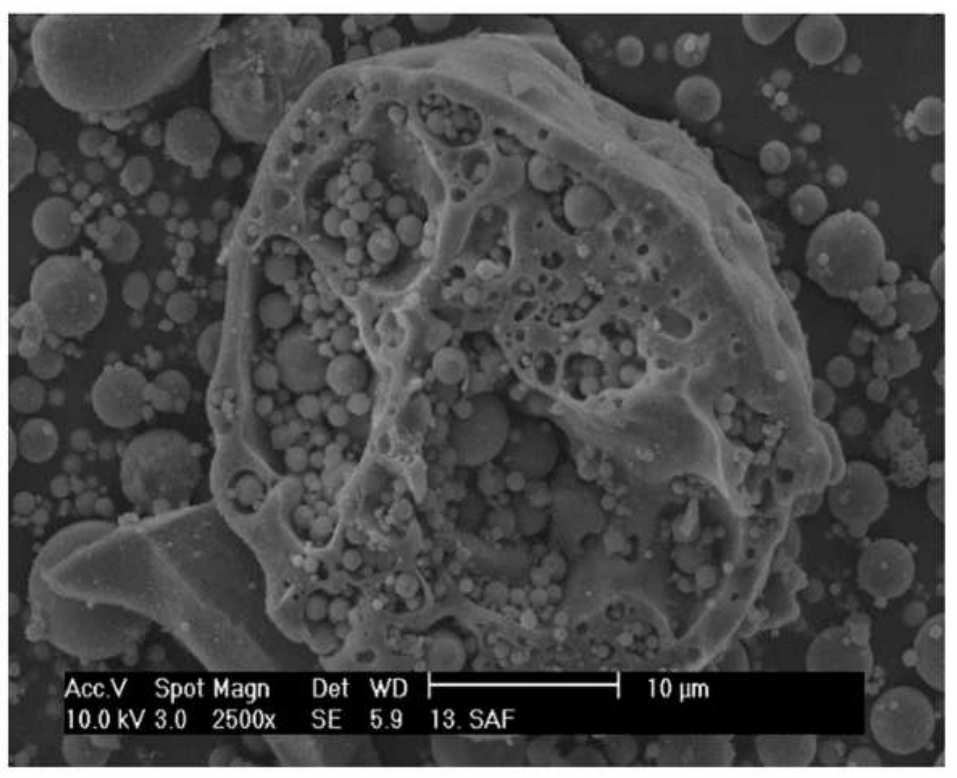

(b) Unburned carbon in Plerosphere form

Figure 4

SEM picture of high carbon ash 


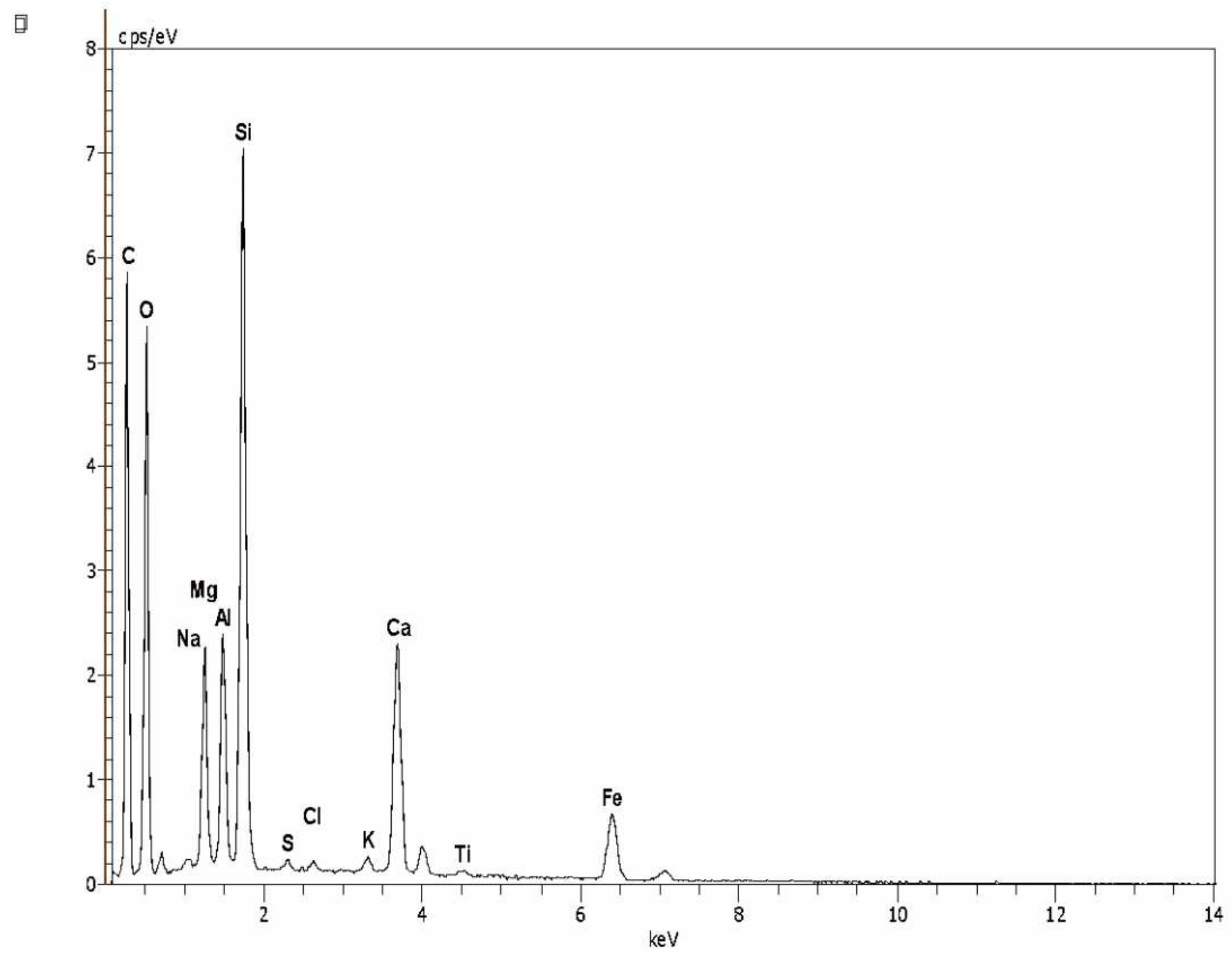

Figure 5

Graph of EDS analysis for high carbon ash

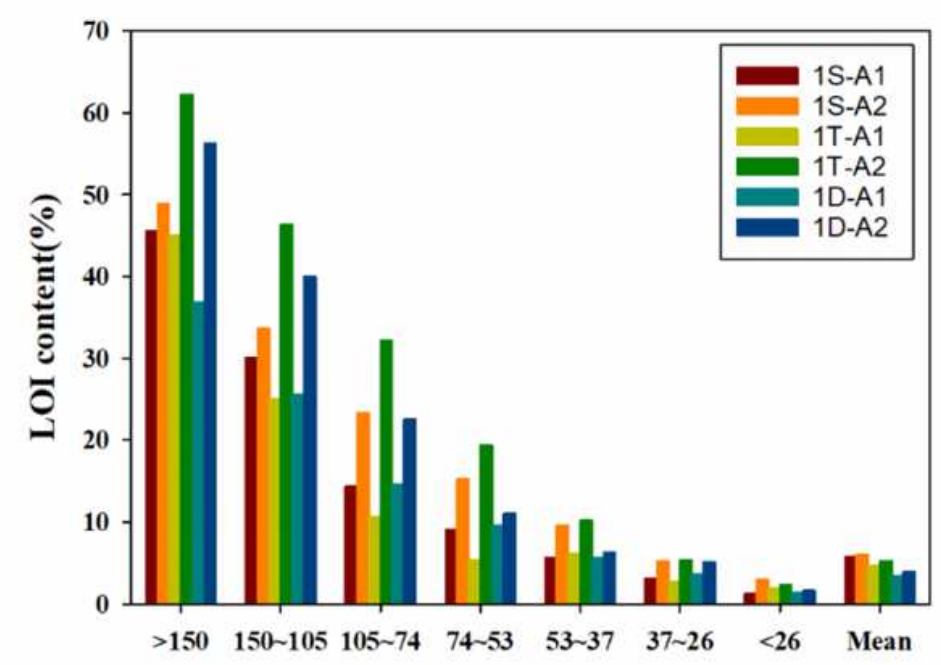

Particle size(um)

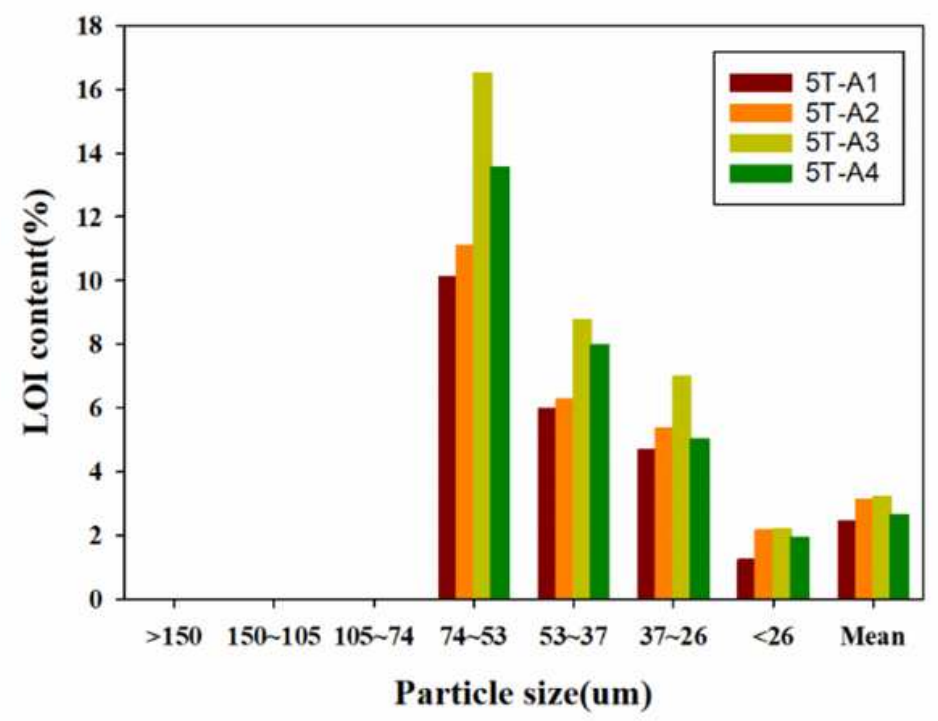


Figure 6

Unburned carbon content of fly ash by ESP layers and particle size

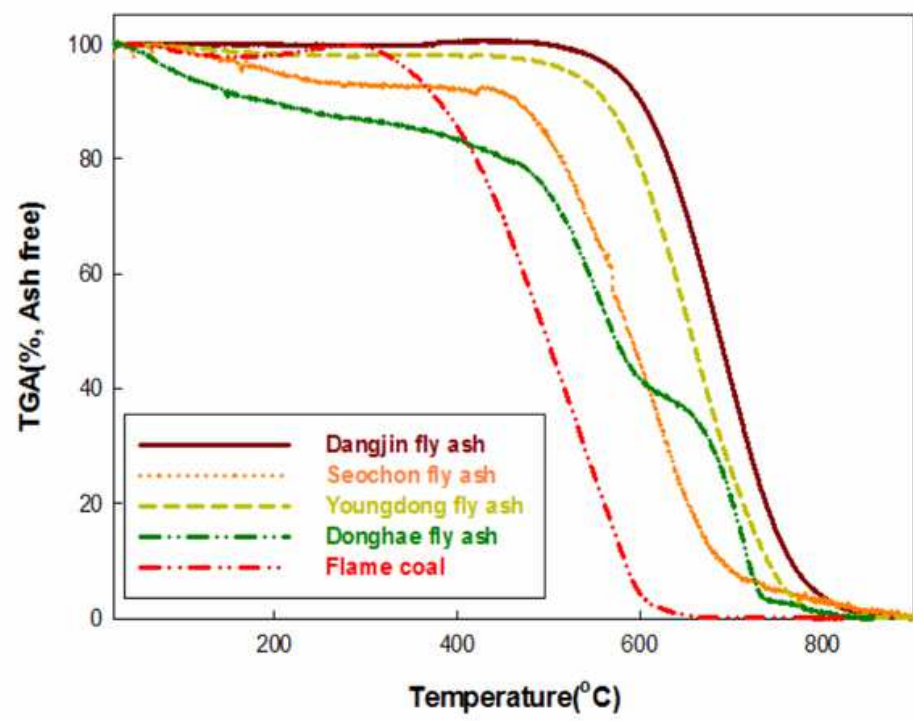

(a) Fly ash

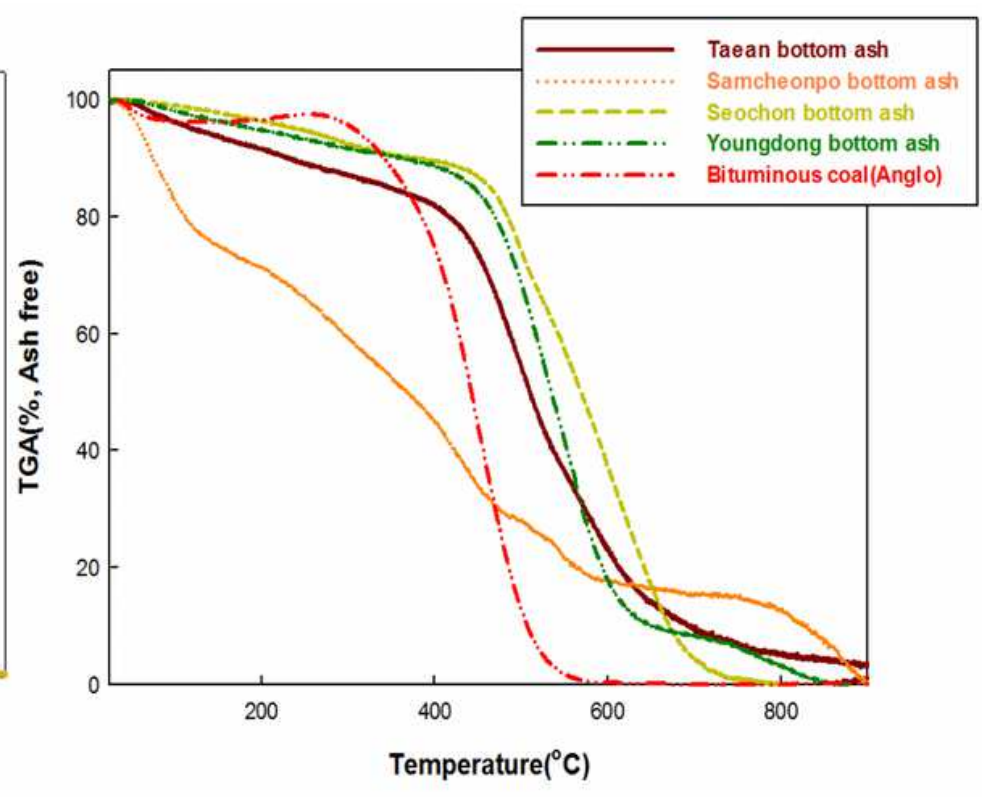

(b) Bottom ash

\section{Figure 7}

Thermogravimetric analysis for high carbon ash

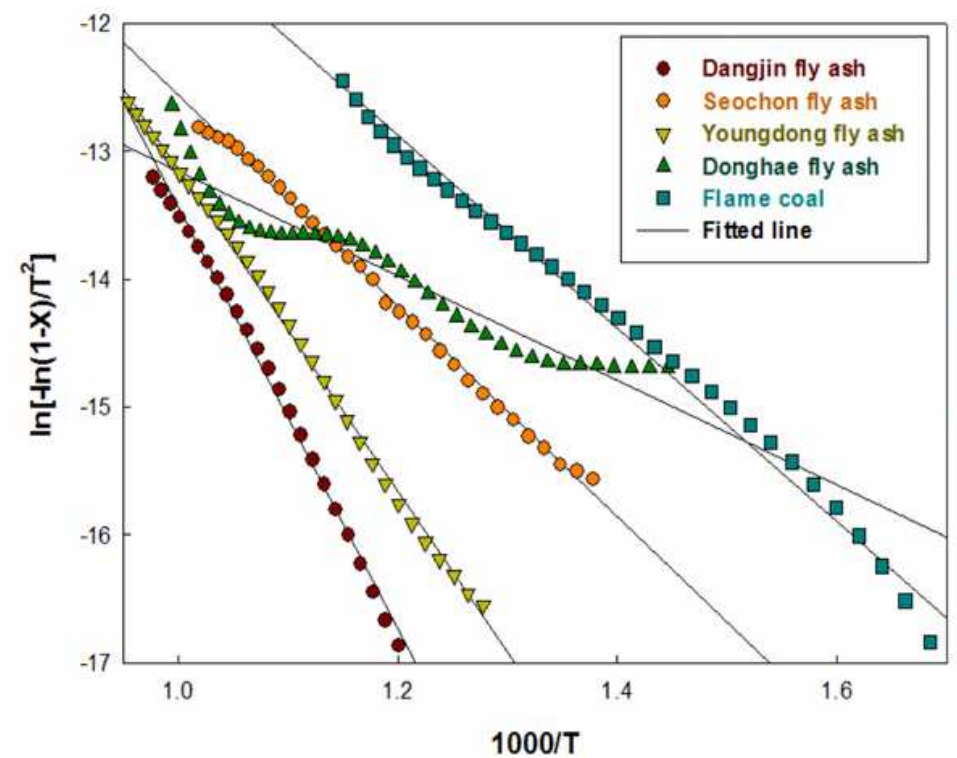

(a) Fly ash

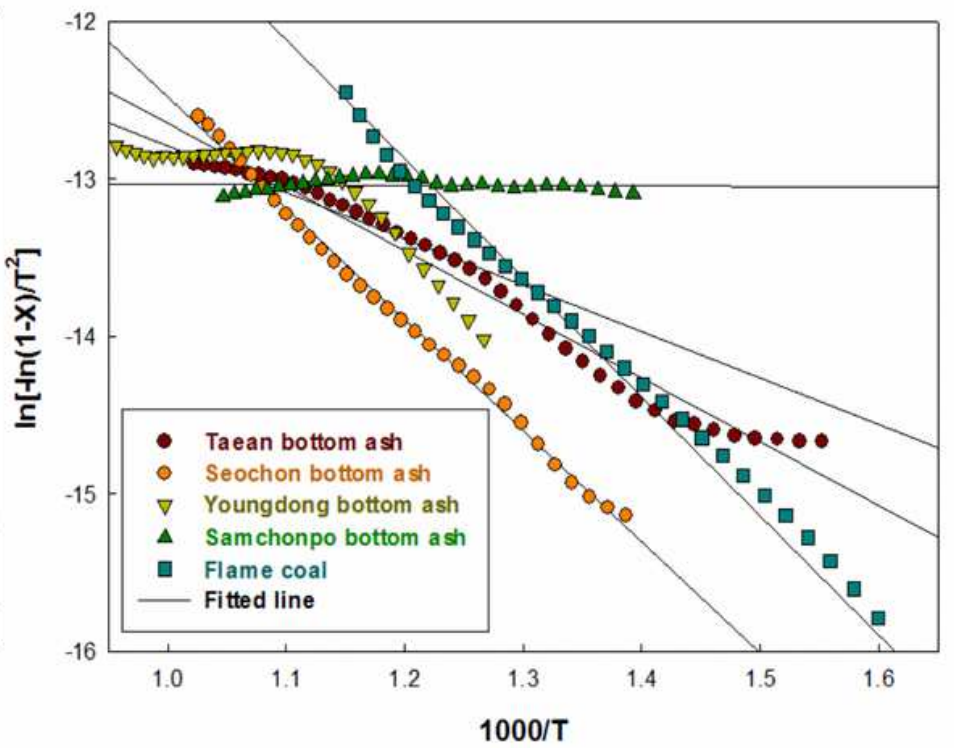

(b) Bottm ash

\section{Figure 8}

Arrhenius plot for high carbon ash 


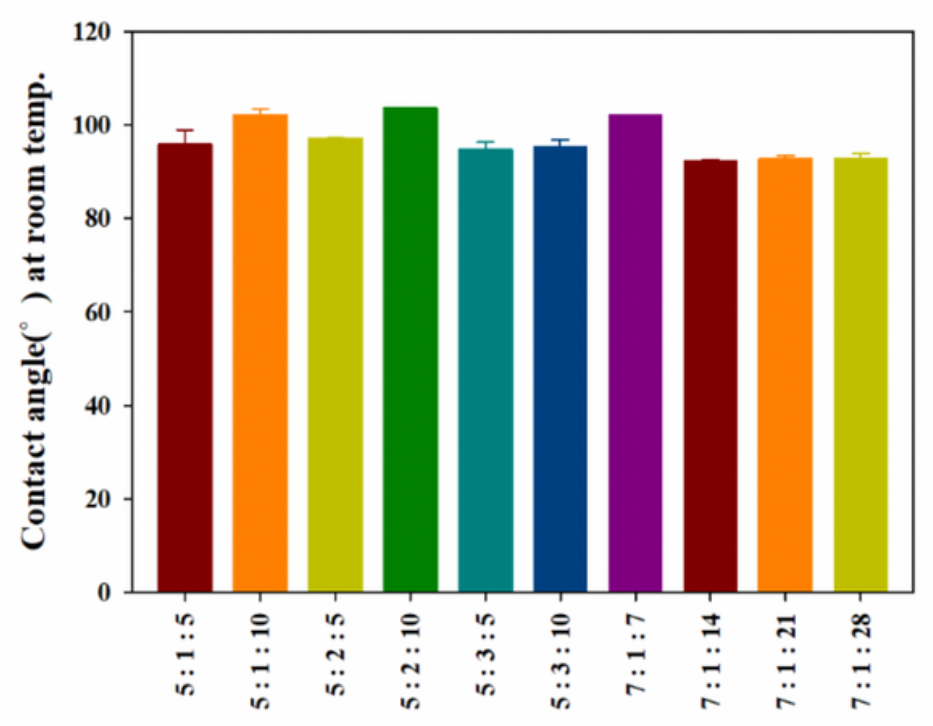

Mixing ratio of ingredients (Asphalt:PFAD:HCA)

(a) Room temp.

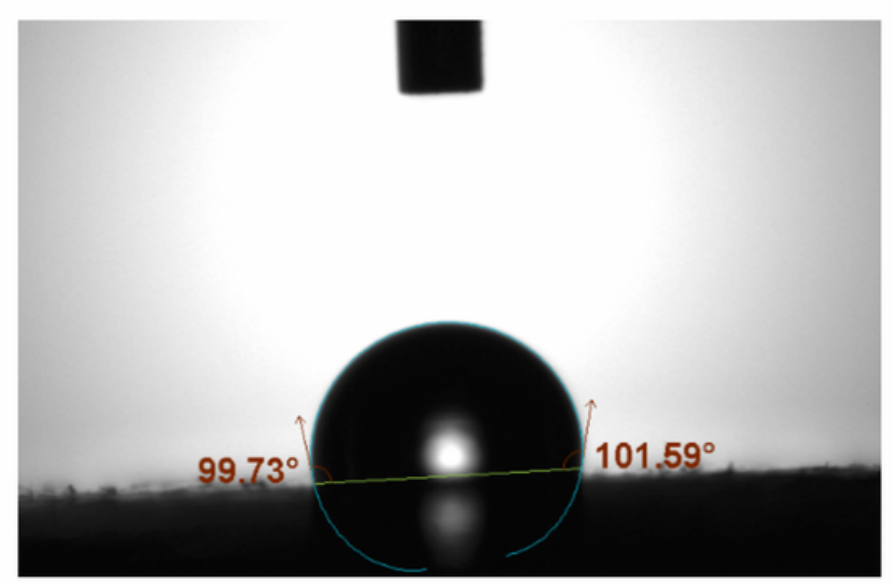

(a) Contact angle (A:P:HCA=5:1:5, room temp.)

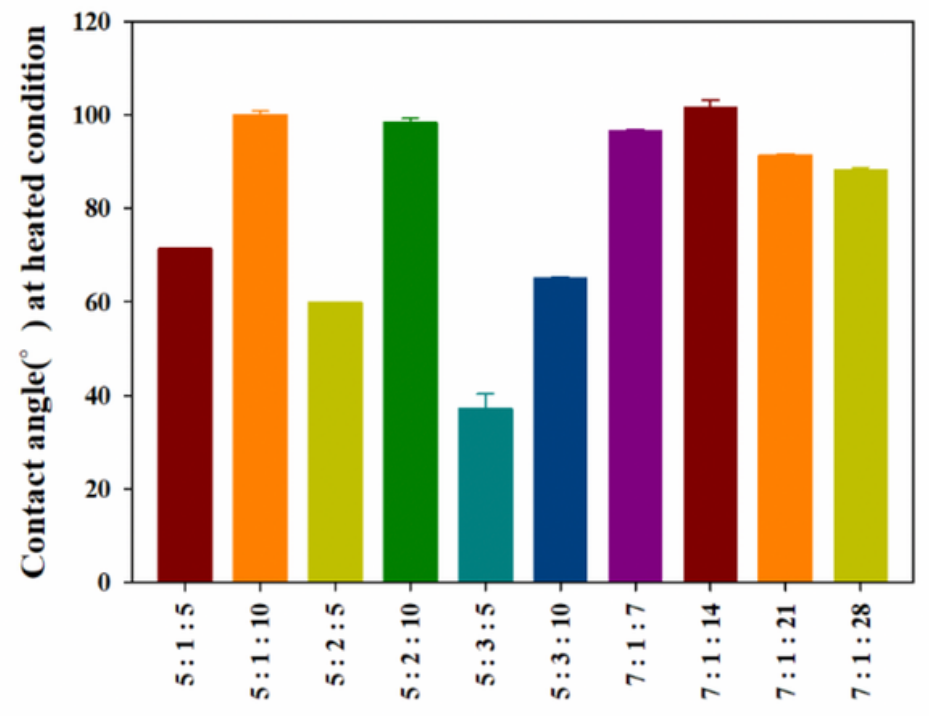

Mixing ratio of ingredients (Asphalt:PFAD:HCA)

(b) Heated condition (about $65 \sim 70^{\circ} \mathrm{C}$ )

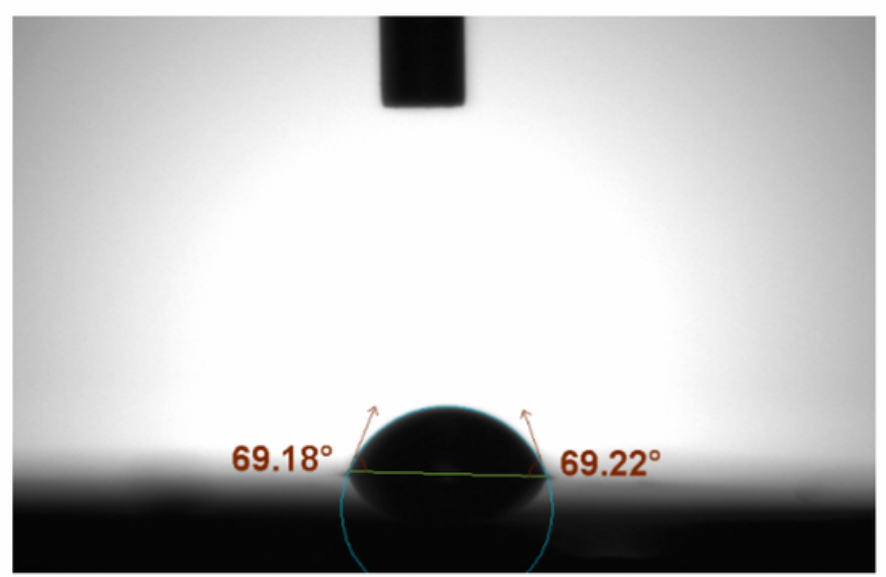

(b) Contact angle (A:P:HCA=5:1:5, heated)

\section{Figure 9}

Contact angle by measuring temperature and mixing ratio of raw materials 


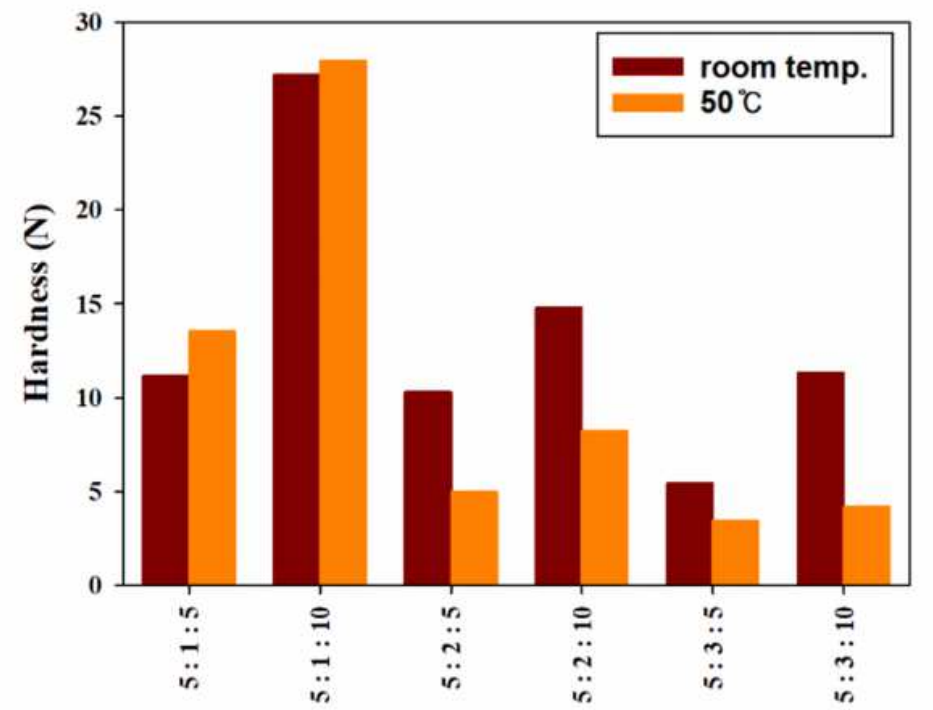

Mixing ratio of ingredients (Asphalt:PFAD:HCA)

(a) Mixing ratio group-1

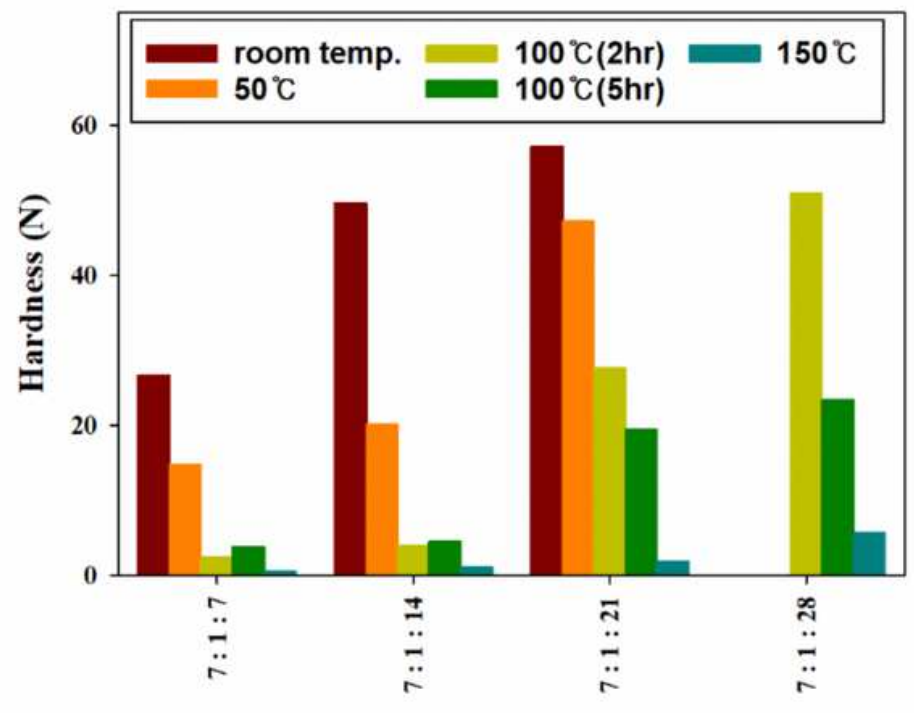

Mixing ratio of ingredients (Asphalt:PFAD:HCA)

(b) Mixing ratio group-2

Figure 10

Hardness by measured temperature and mixing ratio of raw materials 


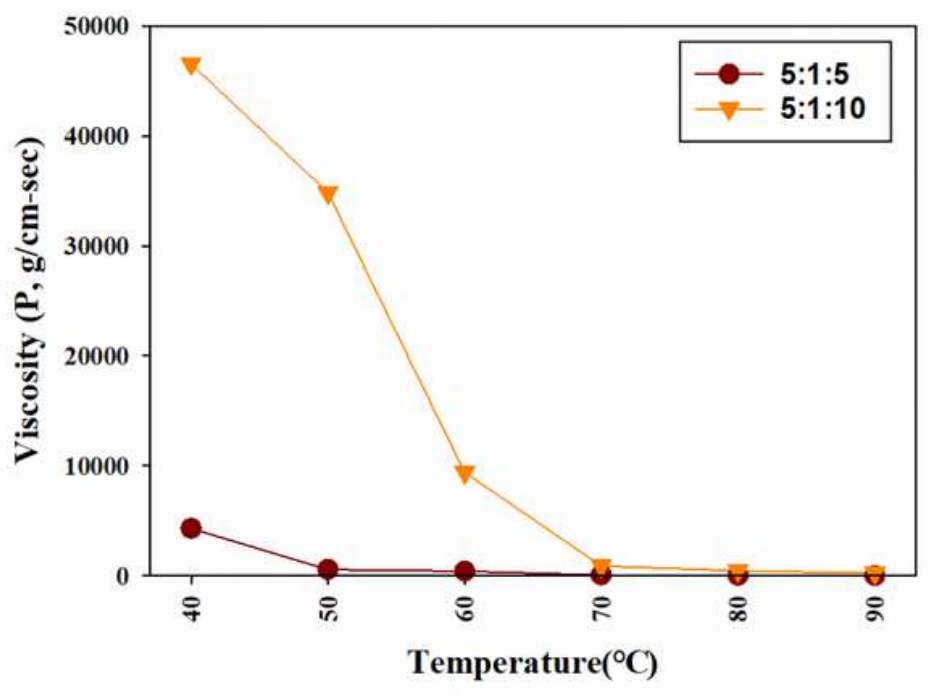

(a) Mixture-1 (Asphalt:PFAD=5:1)

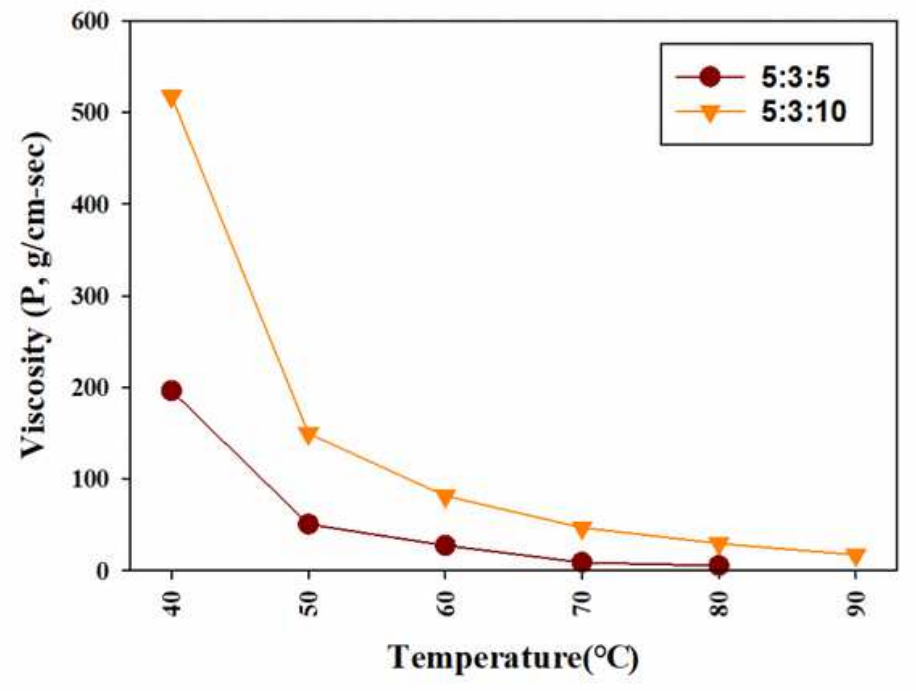

(c) Mixture-3 (Asphalt:PFAD=5:3)

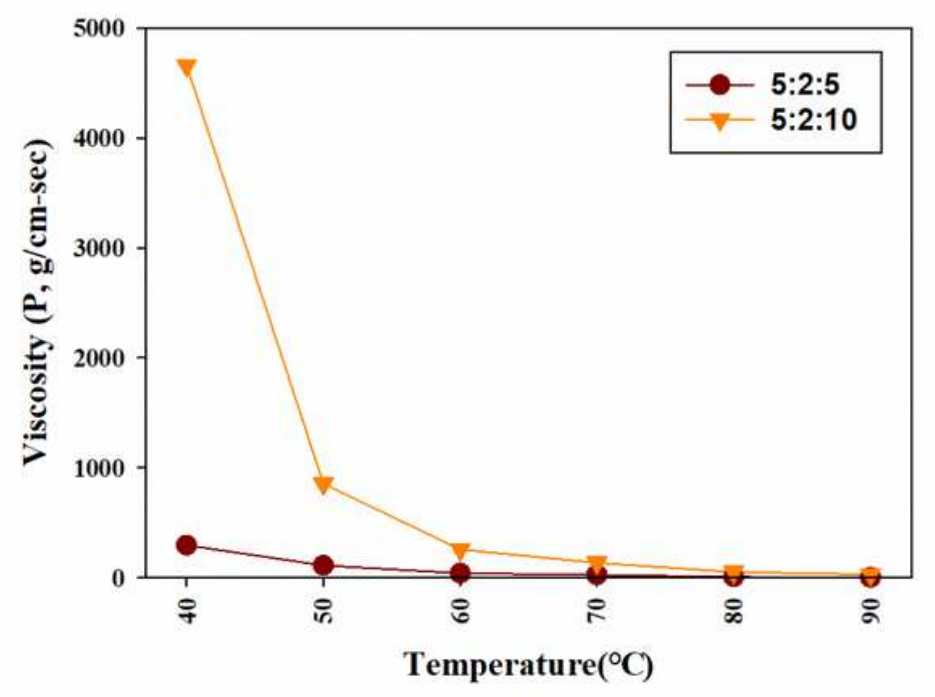

(b) Mixture-2 (Asphalt:PFAD=5:2)

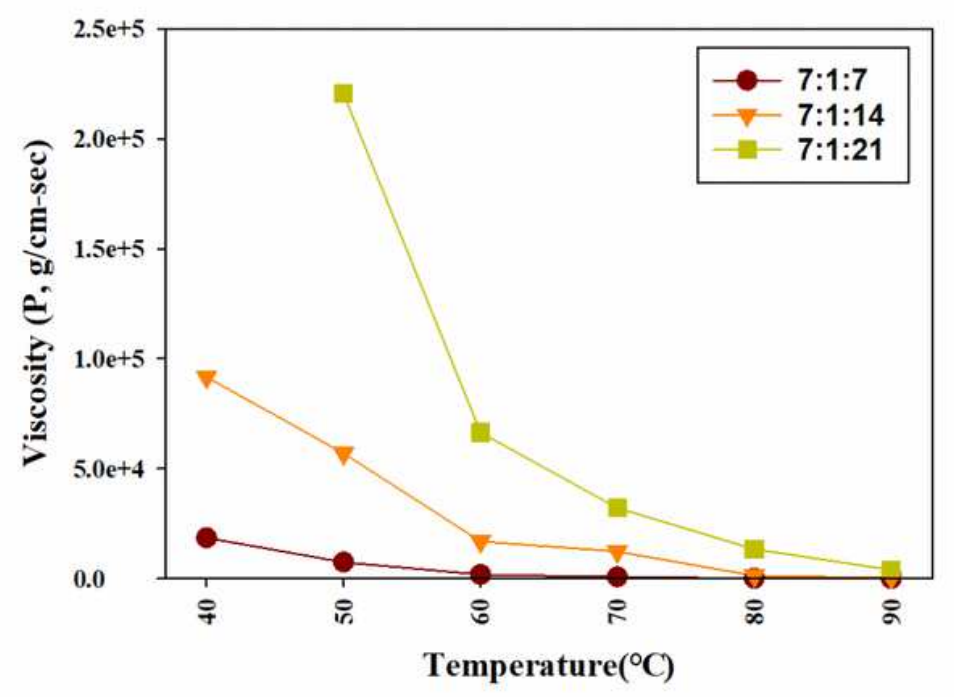

(d) Mixture-4 (Asphalt:PFAD=7:1)

\section{Figure 11}

Viscosity by measured temperature and mixing ratio of raw materials

\section{Figure 12}

Conceptual diagram of applying spontaneous combustion inhibitor and coal stockpile in coal yard 


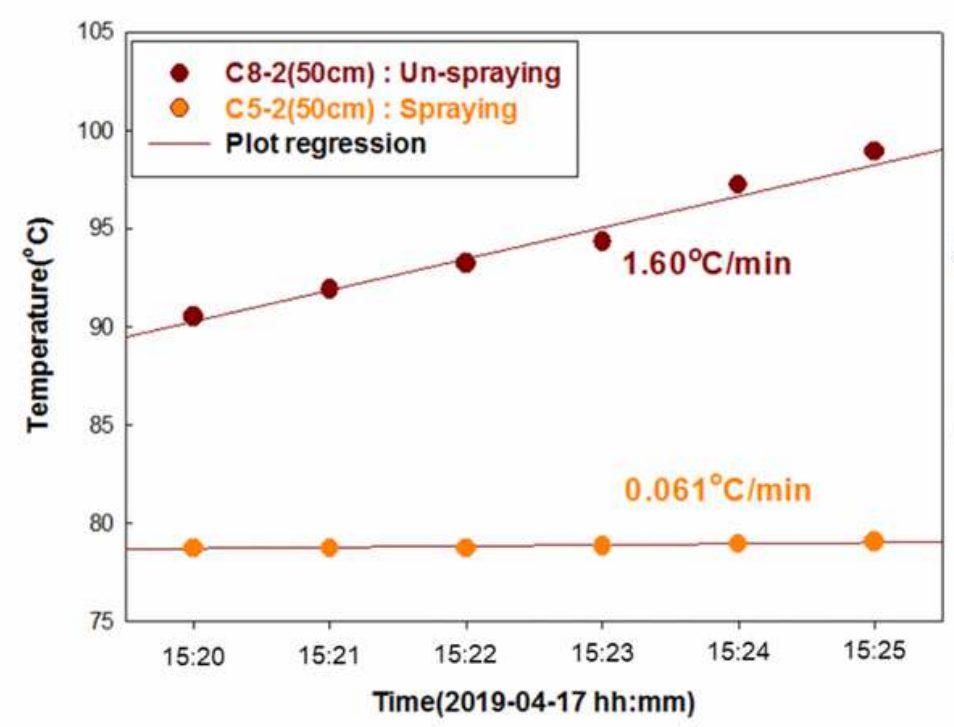

(a) Instantaneous increasing rate of temperature

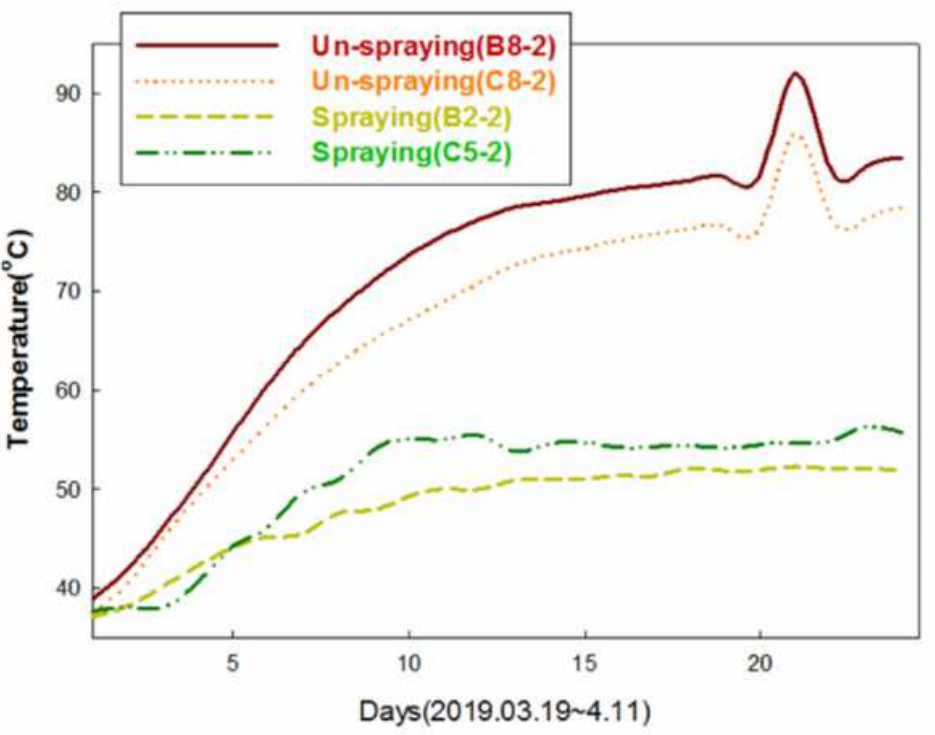

(b) Temperature changes for the entire period

\section{Figure 13}

Comparison of temperature change and instantaneous increasing rate of temperature by application of spontaneous combustion inhibitor

\section{Supplementary Files}

This is a list of supplementary files associated with this preprint. Click to download.

- 20200420tables.docx 